\title{
ANTROPOFAGIA CULTURAL Y TECNOLOGÍA ${ }^{1}$
}

\author{
Cultural cannibalism and technology
}

Horst Nitschack*

\begin{abstract}
RESUMEN
Las vanguardias, tanto las de los países industrializados como las de América Latina, han interpretado las innovaciones técnicas de manera ambigua: ya sea como medios que enriquecen la productividad artística o como amenazas a la creatividad. Para las vanguardias latinoamericanas se complica aun más el escenario, considerando que la modernización tecnológica es una importación de las potencias hegemónicas del norte. Examinamos en este artículo las implicaciones culturales, políticas y religiosas del concepto de antropofagia de Oswald de Andrade. Para él, la práctica antropófaga realizada por el "bárbaro técnizado" o por el "hombre natural tecnizado" significa la humanización de la técnica lo que permite liberar su potencial creativo, un potencial incluso reprimido en los propios países industrializados, convirtiendo de este modo a América Latina, particularmente al Brasil, en una potencia de renovación cultural con validez para toda la humanidad.
\end{abstract}

Palabras clave: Vanguardia, técnica, antropofagia cultural, pesimismo cultural.

\footnotetext{
${ }^{1}$ Este artículo es uno de los resultados del Proyecto Fondecyt $\mathrm{N}^{\circ} 1120116$, titulado: "Rebeldes, malandros, delincuentes y locos: resistencias, transgresiones y expectativas utópicas en la literatura brasileńa del siglo XX".

* Facultad de Filosofía y Humanidades, Universidad de Chile. Santiago, Chile. Correo electrónico: horst.nitschack@gmail.com
}

Artículo recibido el 5 de enero de 2016. Aceptado el 2 de marzo de 2016. 


\begin{abstract}
To the avant-garde, both in industrialized nations and those in Latin America, technological innovations are interpreted ambiguously: as a means of enriching artistic production or as threats to creativity. The situation is even more complex for the Latin American avantgarde, considering that technological modernization is an import from the hegemonic powers of the north. In light of this problem, Mário de Andrade and Oswald de Andrade, members of the Brazilian avant-garde, present two very different alternatives to face the threat of alienating technology: the skepticism of Mário de Andrade contrasts with the optimism of Oswald de Andrade in the Manifiesto Antropófago (Cannibal Manifesto). In this paper we examine the cultural, political, and religious implications of the concept of cannibalism on which the optimism of Oswald de Andrade is founded. To him, the cannibalism practiced by the "technicized barbarian" or by the "technicized natural man" signifies the humanization of technology, allows the liberation of its creative potential, still repressed in the industrialized nations themselves, and makes Latin America, and especially Brazil, a power for cultural renewal that is valid for all of humanity.

Keywords: Avant-garde, technology, cultural cannibalism, cultural pessimism.
\end{abstract}

Los grandes cambios culturales de la época de la modernidad, y del siglo XX en especial, están todos vinculados, y desde una cierta perspectiva podría sostenerse, provocados, por innovaciones técnicas. El siglo pasado se inició con el uso cotidiano de la máquina de escribir y el teléfono en las oficinas y casas, la presencia del auto en las avenidas y plazas de las grandes ciudades y las salas de cine como nuevos espacios de divertimiento ${ }^{2}$. En el ámbito del arte, fueron las vanguardias las que reaccionaron de manera más sensible a estos cambios. Sus distintos movimientos, tanto en Europa como en América Latina ${ }^{3}$, buscaron apropiarse de los nuevos medios técnicos, transformarlos en medios para la producción artística y se posicionaron, cada uno a su manera, entre dos extremos: por un lado, el de la humanización de las nuevas técnicas (como promesa) y, por el otro, el de la tecnificación de lo humano, considerada luego por la mayoría como amenaza. El optimismo inicial de los futuristas alrededor de Marinetti y su primer manifiesto futurista de 1909 en las fuerzas limpiadoras y liberadoras

\footnotetext{
${ }^{2}$ A este respecto se pueden ver estudios tan diferentes en la evaluación de la relación entre técnica y cultura como Schivelbusch, Wolfgang. Geschichte der Eisenbahnreise: Zur Industrialisierung von Raum und Zeit im 19. Jahrhundert. Hanser: München/Wien, 1977; Giucci, Guillermo. La vida cultural del automóvil. Buenos Aires: Prometeo Libros, 2007 y Kittler, Friedrich. Grammophon Film Typewriter. Berlin: Brinkmann \& Bose, 1986.

${ }^{3}$ Ver: Schwartz, Jorge. Vanguardas latino-americanas; polémicas, manifestos e textos críticos. São Paulo: Edusp; Iluminuras; Fapesp, 1995.
} 
de la técnica y su potencialidad de crear una tabula rasa con la posibilidad de construir la humanidad del futuro -que tendrá como condición la destrucción de la antigua-, fue en adelante compartido por pocos. Además, la Primera Guerra Mundial con los millones de muertos en las trincheras y campos de batalla conllevará a un desencanto o, por lo menos, a una evaluación bien diferenciada del progreso tecnológico. No obstante, ni los pesimistas, ni los optimistas dudaron del impacto decisivo de la tecnificación del mundo sobre el arte. Lo comprueba el bien conocido trabajo de Walter Benjamin sobre "La obra de arte en la época de su reproductibilidad técnica” y su tesis sobre la destrucción del aura, que a su vez puede ser leído como un acto liberador o amenazador.

Los choques producidos por las innovaciones técnicas fueron experimentados menos dramáticamente por las vanguardias latinoamericanas. Cierto es quelas naciones americanas pasaron en estás décadas por fases de transformación y modernización. Las vanguardias darán en este contexto impulsos decisivos para la renovación de las literaturas nacionales y su independencia de las metrópolis culturales del norte, mientras que las vanguardias del norte operaron con el objetivo de la transgresión de lo nacional a favor de un internacionalismo y cosmopolitismo artístico.

Justamente, una de las diferencias significativas entre los vanguardistas es su valoración de la técnica y las potencialidades o los peligros que ella acarrea. La antropofagia oswaldiana y su 'bárbaro tecnizado's expresan la convicción de la posibilidad de apropiación y la transformación de su racionalidad alienadora sin prejuicios para la cultura brasileña, considerando sus cualidades 'antropófagas' y su capacidad de convertir lo ajeno en lo propio. El "Manifiesto antropófago" (1928) de Oswald de Andrade es con certeza una de las propuestas más contundentes para la construcción de una cultura independiente de la hegemonía cultural nórdica. Sus provocadoras reflexiones darán inicio a una estrategia de apropiación de las culturas hegemónicas, la 'Antropofagia cultural', que en las últimas décadas ha sido ampliamente discutida por los Estudios Culturales, adquiriendo un importante reconocimiento en dicho ámbito 5 .

\footnotetext{
4 "O homem natural. Rousseau. Da Revolução Francesa ao Romantismo, à Revolução Bolchevista, à Revolução Surrealista e ao bárbaro tecnizado de Keyserling. Caminhamos.” Andrade, Oswald de. "Manifesto antropófago", En: Andrade, Oswald de. A utopia antropofágica. São Paulo: Editora Globo, (1990): 48.

5 Cf. especialmente los siguientes trabajos: Keck, Anette / Inka Kording / Anja Prochaska (eds): Verschlungene Grenzen Antropophagie in Literatur und Kulturwissenschaften. Literatur und Anthropologie. Tomo 2, Tübingen: Narr, 1999.; Jauregui, Carlos A. Canibalia. Canibalismo, calibanismo, antropofagia cultural y consumo en América Latina. Madrid: Vervuert, 2008; Nunes, Benedito. "Antropofagia ao Alcance de todos". En: Andrade, Oswald de. A utopia antropofágica. São Paulo: Editora Globo, (1990): 5 - 39; Rocha, João Cezar de Castro y Ruffinelli, Jorge (Eds.). Anthropophagy Today? Nuevo Texto crítico, Año XII, (1999), No. 23/24.
} 
La antropofagia oswaldiana se presenta como un acto provocador. Ella emerge en el contexto de las discusiones sostenidas por los vanguardistas brasileños (que se intitularon como 'modernistas') en los años veinte en São Paulo sobre las estrategias de una literatura nacional para contribuir a la (re)fundación de una 'brasilidade' auténtica ${ }^{6}$. Son los años en los cuales esta ciudad vive cambios decisivos, primero la modernización impulsada por la riqueza, resultado de la exportación del café, y después por la crisis, provocada por el colapso de esta exportación, consecuencia de la crisis económica mundial 7 . Dentro del modernismo brasileño el movimiento antropofágico fue el más original y reunió los nombres más destacados, entre ellos: Oswald de Andrade, Mário de Andrade, Tarsila do Amaral, Raul Bopp, Menotti del Picchia.

Sin duda, el "Manifiesto Antropófago", con sus formulaciones ingeniosas, divertidas, irreverentes - a veces cínicas- e irónicas, se ha convertido en el más exitoso de todos los manifiestos de la época. El slogan "Tupi or not Tupi, that is the question" ${ }^{-}$-cuya apropiación y transformación de la cita del Hamlet shakespeariano en sí mismo es un ejemplo de una práctica antropófaga-, se ha convertido en el lema del movimiento. El enunciado debe ser leído en múltiples niveles, pero la transformación más significativa radica en la substitución del "to be" por "Tupi”, el nombre de una tribu antropófaga. En él, la cuestión fundamental no es la interrogación por el ser abstracto -como lo formula Hamlet- sino por una práctica que organiza la convivencia social al nivel ritual, es decir, corporal, simbólica y religiosamente, y al nivel de las relaciones de poder político, como la antropología entiende la antropofagia. Esta antropofagia, "Única lei do mundo", tiene vigencia universal, pero fue reprimida y suprimida en las culturas occidentales "civilizadas" por un universalismo idealista y abstracto. En la cultura brasileña, sin embargo, según la argumentación de Oswald de Andrade, aun está presente ${ }^{10}$. Gracias a ella los colonizados resistieron durante siglos contra los colonizadores y lograron finalmente transformar su inferioridad en superioridad. Antropofagia aparece entonces como la unidad aun no cuestionada entre naturaleza y cultura. En ella las leyes de la naturaleza se convierten en leyes de la cultura. De esta identidad entre naturaleza y cultura resulta su superioridad como estrategia

\footnotetext{
${ }^{6}$ Las referencias más importantes son el Manifiesto antropófago de 1928 y la Revista de Antropofagia (1928 - 1929) de la que se publicó un total de 25 números.

${ }^{7}$ Sevcenko, Nicolau. Orfeu extático na Metrópole. São Paulo, sociedade e cultura nos frementes anos 20. São Paulo: Compahia das Letras, 1992.

${ }^{8}$ Op. cit. Andrade, "Manifesto...", p. 47.

${ }^{9}$ Ibid, p. 47.

${ }^{10}$ Se menciona a Freud y se hace alusión a su texto Totem y Tabu (Totem und Tabu, 1913), no obstante, sin citar las referencias precisas. El otro texto de Freud en el cual hace pensar el manifiesto, El malestar en la cultura (Das Unbehagen in der Kultur, 1930) todavía no había sido publicado.
} 
cultural. Así, antropofagia no sería solamente la práctica cultural con la cual el subalterno mantiene su identidad frente a las culturas hegemónicas, antropofagia sería también el procedimiento de la renovación cultural con validez para toda la humanidad. Es una propuesta de intelectuales latinoamericanos de inicios del siglo XX, comparable con La raza cósmica de José de Vasconcelos, en torno a cómo la cultura del futuro podría emerger de este continente, una propuesta, en la cual lo que ha sido considerado motivo de inferioridad se transforma en superioridad frente a las culturas hegemónicas. Por la antropofagia las manifestaciones culturales descalificadas como 'imitación', como 'copia', como resultados de 'influencias', son así redefinidas y resemantizadas como prácticas de apoderamiento.

Los objetos de la digestión antropofágica son, por supuesto, todo el patrimonio cultural de los poderes hegemónicos, sus conocimientos y sus ciencias, pero también sus tecnologías y sus invenciones técnicas. En estas últimas la modernidad se ha materializado en consecuencias concretas para la convivencia cotidiana y de ahí que representen el desafío más grande. Frente a ellas los intelectuales latinoamericanos se encuentran expuestos a un dilema, o a una contradicción bastante compleja: la liberación de la colonialidad no puede renunciar a las tecnologías avanzadas, desarrolladas por los poderes hegemónicos y ello trae el peligro de generar una nueva dependencia de estos poderes.

Consecuentemente, la apropiación de la técnica y su humanización no fueron solamente un programa de las vanguardias, sino, desde los años veinte, también se convirtieron en una de las reivindicaciones centrales de los partidos comunistas. A partir de los años 30, Oswald de Andrade se acercará al Partido Comunista (ingresará al partido en 1931), lo que conllevó a su distanciamiento de la antropofagia ${ }^{11}$. Después de la Segunda Guerra Mundial, no obstante, se retirará del Partido Comunista y retomará en su ensayo sobre "A Crise da Filosofia Messiânica" (1950) su pensamiento antropófago, ahora no con formulaciones polémicas, como en el Manifiesto, sino con una intensión claramente utópica. Sostiene que la 'antropofagia' debe ser considerada como una "Weltanschauung" ('visión del mundo' - en el original en alemán), es decir, un pensamiento en el cual se incluyen los tres discursos principales a partir de los cuales se define nuestra posición en el mundo: el cultural, el político y el religioso. Este cruce entre lo cultural, lo político y lo religioso en la antropofagia se produce para Oswald de Andrade en dos ejes, como revela un análisis de sus textos principales, desde el "Manifiesto" al texto póstumo, "A marcha das utopias"12: el eje diacrónico y el sincrónico. El primero es la historia de la colonialidad y el segundo

\footnotetext{
${ }^{11}$ Ver el prefacio de su novela Serafim Ponte Grande, publicada en 1933 y Fonseca, Maria Augusta: Oswald de Andrade. Biografia. São Paulo: Editora Globo, 2007.

${ }^{12}$ Andrade, Oswald de: "A utopia Antropófaga" En: Andrade, Oswald: A utopia antropofágica. São Paulo, Editora Globo, (1990): 161-209.
} 
la modernidad tecnológica. Es decir, la "antropofagia" opera como una metáfora mediante la cual se piensa la constelación entre cultura -política y religión frente a los desafíos históricos de la colonialidad y las potencialidades actuales que ofrece el uso de las técnicas más avanzadas. De esta manera la "antropofagia" se convierte en una estrategia cultural (identidad y autonomía), política (decolonización) y religiosa (lo ritual, lo mítico, lo mesiánico) para sociedades que están en camino de superar la colonialidad y buscan apoderarse de medios técnicos avanzados para realizar su proyecto-. Así por los menos Oswald de Andrade va a presentarlo en "A Crise da Filosofia Messiânica"13 en la propuesta de convertirse en una humanidad liberada. El proyecto de Oswald de Andrade es el de un universalismo liberado (¡no liberal!). Un universalismo que supera el logocentrismo represor del mundo nórdico-occidental y lo substituye por una nueva ley, "Única lei do mundo"14, la ley de la antropofagia, que nos une a todos.

En "A Crise da Filosofia Messiânica"15 de 1950 Oswald de Andrade será muy explícito: la ley fundamental es la ley de la deglutación que, según él, es la ley de la vida, la ley en el cual se reúnen el amor y la muerte o, según Freud -el autor más citado en el "Manifiesto"-, la pulsión de vida (eros) y la pulsión de muerte. Sin embargo, el autor se distancia de Freud en un punto fundamental: el inicio de la cultura para Oswald de Andrade no es el asesinato del padre por la horda de los hermanos, y la interiorización simbólica de su ley por el banquete antropófago en el cual los hermanos comen al padre ${ }^{16}$, sino que el fundamento de la cultura es el matriarcado. Refiriéndose a los trabajos del antropólogo suizo J.J. Bachofen (1815$1887)^{17}$, considera el orden matriarcal como el primer orden de la humanidad, un orden que se encontraría en concordancia con la propia naturaleza. Su antítesis es el orden del patriarcado: culturalmente concebido como el mundo del hombre civilizado, del logocentrismo, de la racionalidad, de la tecnología; políticamente es comprendido como el mundo de la dominación del individuo por el Estado, por los sistemas de administración y por la colonialidad (este concepto no aparece como noción pero está implícitamente aludido); religiosamente (como compensación del sufrimiento y de los deseos frustrados) es el mundo de las promesas mesiánicas que se cumplirían en un más allá.

13 Andrade, Oswald de: "A Crise da Filosofia Messiânica". En: Andrade, Oswald: A utopia antropofágica. São Paulo, Editora Globo, (1990): 101-147.

${ }^{14}$ Op. cit, Andrade, "Manifiesto antropófago", p. 47.

${ }^{15}$ Presentada como "Tese para concurso da Cadeira de Filosofia da Faculdade de Filosofia, Ciências e Letras da Universidade de São Paulo".

${ }^{16}$ Como plantea Freud en Totem y tabu y en El Malestar en la cultura.

${ }^{17}$ Bachofen, Johann Jakob. El matriarcado: Una investigación sobre el carácter religioso y jurídico del matriarcado en el mundo antiguo (1861) - conocido principalmente a través de las referencias en Friedrich Engels: Origenes de la familia, de la propiedad privada y del Estado. 
La síntesis -también en este concepto dialéctico de tesis, antítesis y síntesis Oswald de Andrade permanece fiel a Hegel y a la filosofía idealista- la síntesis, decíamos, sería el "hombre natural tecnizado" ${ }^{18}$ o, como aparece en el "Manifiesto" en referencia al filósofo y viajero alemán Hermann Keyserling, "el bárbaro tecnizado" 19.

Los logros deestemodelo para un pensamientolatinoamericanoson evidentes: el pasado antropófago y matriarcal, que ha sido cubierto apenas superficialmente por la colonialidad -su modernidad y sus manifestaciones sirvieron solamente de máscara, pero, según Oswald de Andrade, nunca penetraron profundamente este mundo tropical-, se presenta entonces como la condición para una nueva reconciliación del hombre con la naturaleza, en la cual en este momento histórico de la humanidad se integrará la tecnología ${ }^{20}$. En otras palabras: a la liberación de la tecnología y su uso, devendrá el "hombre natural tecnizado", que está en contacto íntimo con la antropofagia, es decir, con la ley de la deglutación, de las pulsiones de eros y muerte y el matriarcado, y no el "hombre civilizado", que se ha convertido en esclavo de su propia tecnología ${ }^{21}$. Este "hombre natural tecnizado" es el sujeto que gracias a sus capacidades 'antropofágicas' está en condiciones de 'deglutir' la propia tecnología y así humanizarla.

La crítica de la cultura de la tradición occidental, cuyo primer representante célebre fue J.J. Rousseau, había derivado a inicios del siglo XX en un pesimismo cultural, asociado con el nombre de Spengler ${ }^{22}$. Oswald de Andrade retoma esta tradición, pero desde una perspectiva optimista, postulando una crítica según la cual América Latina se convierte en laboratorio de una nueva humanidad. En todos los textos de Oswald de Andrade se hace evidente que este mantiene un diálogo permanente -algunas veces polémico y otras irónico- con un representante nórdico-occidental del pesimismo cultural, Sigmund Freud. En el modelo freudiano del nacimiento de la cultura el acto antropofágico juega un papel decisivo. El "malestar en la cultura", contra el cual el "Manifiesto antropófago" exclama "A alegría é a prova dos nove" 23 es según Freud la consecuencia de una

\footnotetext{
${ }^{18}$ Op. cit. Andrade. “A crisis...”, p. 103.

${ }^{19}$ Op. cit. Andrade, "Manifiesto...", p. 47.

${ }^{20}$ Existe un paralelo con el pensamiento de Carlos Mariátegui, para quien el socialismo incaico (el Ayllú) constituía el fundamento para la realización de una sociedad socialista en América Latina, de modo que no es necesario el paso por el capitalismo y la industrialización, como lo ha previsto la teoría marxista clásica. Ver: Nitschack, Horst. "O mito do índio no modernismo brasileiro e nas vanguardas hispanoamericanas.” En: Berg, Walter Bruno. As Américas do Sul: O Brasil no Contexto Latino-Americano. Beihefte zur Iberoromania Bd. 17. Tübingen: Max Niemeyer, (2001): 108-118.

${ }^{21}$ Op. cit. Andrade, A crisis, p. 103.

${ }^{22}$ Oswald Spengler y El ocaso del occidente, primera edición del primer tomo en 1918, autor también citado por O. de Andrade en el Manifiesto.

${ }^{23}$ Op. cit. Andrade, "Manifiesto...", p. 51.
} 
escena originaria de represión (Verdrängung): el asesinato del padre por sus hijos varones y el acto ritual de devorarlo. La transformación de este tabú en tótem será el primer acto cultural. Así, el malestar, provocado por un sentimiento de culpa, cuyo origen ha sido suprimido para siempre, es, para Freud una sensación y una experiencia permanente e inherente en toda cultura hasta el punto de afirmar que donde no hay malestar no puede haber cultura. Estructuralmente, este malestar es el resultado de lo no-representado, de lo inefable y de lo innombrable que atraviesa nuestra cultura.

La antropofagia rompe así con esta concepción de la represión inevitable y fundadora de la cultura de manera provocadora y propone pensar una práctica cultural en una sociedad libre de represión, lo que no significa libre de agresión. Esta sociedad del ocio y de la convivencia dionisíaca, construida sobre el rito antropofágico, abarca también la dimensión religiosa. No de una religión mesiánica a la espera de una redención en el más allá, sino una conciliación con la naturaleza y sus dos leyes fundamentales: el amor y la muerte, en el propio ritual. La práctica antropofágica, por consecuencia, en sus distintas dimensiones -la cultural, política y religiosa- debe ser reconocida como el origen de una cultura que no se disfraza, no disimula, no se desplaza ni se silencia a sí misma ${ }^{24}$. Ella sería lo opuesto a la cultura occidental, fundada sobre una represión originaria, razón por la cual es una cultura de un profundo malestar. En este sentido la antropofagia sería 'origen' como Heidegger lo piensa en "El origen de la obra de arte”, 'origen' en las distintas significaciones que la palabra alemana "Ursprung” evoca, 'origen', donde aparece la "aletheia", la verdad 25 . Sin embargo, el lugar donde se produce esta abertura del origen no sería el arte, como lo imagina Heidegger, sino en la práctica de la comunidad, la práctica cultural, política y religiosa.

Como señalamos, para Freud lo innombrable marca profundamente la estructura de la cultura en general. En su análisis de la técnica, especialmente en sus dos discursos famosos "La técnica" y "La vuelta"26, Heidegger constata un fenómeno muy parecido. Sus reflexiones sobre el carácter ontológico de la técnica revelan en el 'ser' de la técnica estructuralmente el mismo estado de cosas: como la cultura, la técnica disimula su propio ser, lo que Heidegger describe con el concepto

\footnotetext{
${ }^{24}$ En alemán existe un verbo que incluye o sintetiza todas estas distintas significaciones: "verstellen": desplazar, bloquear, disfrazar, disimular, fingir. Con ello tenemos sintetizado en este verbo "verstellen" todos los procesos que caracterizan una cultura no redimida - y también la técnica no redimida.

${ }_{25}$ Heidegger, Martin: "Der Ursprung des Kunstwerkes", En: Heidegger, Martin. Holzwege. Frankfurt am Main: Vittorio Klostermann, (1980): 36.

${ }^{26}$ Traducciones de estos discursos se encuentran en: http://www.heideggeriana.com.ar/textos/ tecnica.html ("La pregunta por la técnica") y http://www.heideggeriana.com.ar/textos/la_vuelta. html ("La vuelta").
} 
de “Gestell”. El verbo alemán presente en la raíz de esta denominación nos remite a tres significaciones contrarias:

1. La técnica como "Gestell” disimula a sí misma sus propias potencialidades y en su ser disimulado, "Verstellung", domina todo ${ }^{27}$.

2. Sin embargo, ella también nos "confronta, para, detiene". Experimentar con ella (Erfahrung) evidencia un peligro (Gefahr) que nos amenaza con la muerte (perecer), un sentido etimológico que se encuentra también en castellano, en "perecer", la raíz común de las palabras "ex - periencia” y “peligro". La técnica nos confronta con un peligro, es un desafío, pero para Heidegger - que cita en este contexto varias veces los versos de Hölderlin: "Wo aber Gefahr ist / wächst das Rettende auch": "Dónde hay peligro I crece lo que nos salva." O: "crece lo salvador" - la técnica tiene una potencialidad salvadora, que está disimulada en ella ("verstellt") y que la cultura occidental aun no logra liberar.

3. Pero aun otro sentido - muy distinto- está también presente: "poner" que etimológicamente nos refiere a 'poesía': el acto poético que, en su dimensión creativa, pone algo en el mundo. Asimismo, la técnica redimida, según la propuesta filosófica de Heidegger, estará dotada de fuerza poética.

En otras palabras, según el pensamiento de Heidegger se repite en la técnica lo que Freud ha diagnosticado para la cultura (occidental): hay algo innombrable dentro de ella, que no permite que aparezca y que solamente en un estado redimido podría revelarse.

Este diagnóstico de que la propia realidad no se revela, sino que se disimula a sí misma, se repite en un tercer discurso fundador del pensamiento moderno: en lo que Marx llamaba el carácter 'fetiche' de la mercancía ${ }^{28}$. Así se produce la conciencia falsa de los productores frente a los medios de producción que no aparecen tal y como son, es decir, como relaciones sociales, sino como relaciones de cosas (y de este modo no dispuestos a cambios). En consecuencia, nuestro pensamiento político estaría cegado por la cosificación de las relaciones sociales y los actores pierden la posibilidad de lograr una conciencia adecuada de su propia situación.

Para la cultura antropófaga este diagnóstico, que se repite, cierto es, con argumentos muy distintos en Marx, Freud y Heidegger, no tendría validez. Su 'Verstellung', su mascarada o enmascaramiento, sería una estrategia consciente y calculada, no un acto inconsciente, un resultado de las condiciones de producción

\footnotetext{
${ }^{27}$ Heidegger, Die Technik und die Kehre, p. 37.

${ }^{28}$ Marx, Karl. Das Kapital, Berlin: Dietz Verlag, (1970): 87.
} 
capitalista, o una fatalidad ontológica. De ahí resulta la superioridad de la cultura del colonizado: no de la dialéctica hegeliana y sus consecuencias para la relación entre amo y siervo, tampoco, como Silviano Santiago argumenta, de su condición de generarse desde un entre-lugar, sino de la pervivencia de lo antropófago ${ }^{29}$.

Desde la antropofagia se resta también importancia a los argumentos de Roberto Schwarz contra las 'ideas fuera del lugar', considerando la necesidad de preguntarnos -siguiendo su análisis- si lo que vale para las ideas, no valdría también para los “objetos" y las "prácticas técnicas” que también se encuentran "fuera del lugar" 30.

El optimismo con respecto al uso de las tecnologías modernas que encontramos en Oswald de Andrade, no se justifica solamente por la distancia geográfica del continente sudamericano con respecto a la catástrofe de la Primera Guerra Mundial, donde se manifestó de manera trágica la potencia destructiva de las técnicas modernas y la civilización se convirtió en barbarie ${ }^{31}$. Su optimismo se legitima también en la cualidad antropofágica de la cultura brasileńa. Ella le restaría el carácter alienador a la técnica y contribuiría a su humanización.

Tanto para Marx como para Heidegger -más allá de todas las diferencias que existen entre sus planteamientos- la condición principal para el uso liberado y realmente humano de los medios de producción, y con ello de la técnica moderna, es la ruptura con la continuidad de la historia, ya sea en el pensamiento de Heidegger el regreso al 'origen' (Ursprung) -a la fisura originaria- o en el programa

\footnotetext{
${ }^{29}$ No cuestionamos en este contexto este pensamiento oswaldiano, pero queremos mencionar dos objeciones de peso: la primera podría apoyarse en las observaciones de Horkheimer y Adorno en la Dialéctica de la Ilustración: Constatan el carácter ideológico de la Ilustración, tanto en su pretensión de figurar como verdad universal, como en la presencia oculta de un pensamiento mágico, pero insisten que el pensamiento mágico ocultado por la Ilustración, también es falsedad, una 'falsedad sangrienta'. Su única ventaja en comparación con el pensamiento ilustrado consiste en el hecho de que este no oculta su carácter dominador. "Magie ist blutige Unwahrheit, aber in ihr wird Herrschaft noch nicht dadurch verleugnet, dass sie sich, in die reine Wahrheit transformiert, der ihr verfallenen Welt zugrunde legt" (Horkheimer, Max y Adorno, Theodor: Dialektik der Aufklärung, Frankfurt: Fischer, 2000 (1era edición 1947): 15.

La otra objeción podría fundamentarse en un examen detenido de la influencia del darwinismo y la idea de la sobrevivencia del más adaptado (no del más fuerte como reza su popularización) en el manifiesto oswaldiano.

${ }^{30}$ Ver: Schwarz, Roberto. "Idéias fora do lugar". En: Schwarz, Roberto. Ao vencedor as batatas. São Paulo: Livraria Duas Cidades, 1992 (1era edición 1977): 13-28.

${ }^{31}$ El optimismo técnico propio de las vanguardias europeas de la época anterior a la Gran Guerra sufrió con esta guerra una desilusión radical. Solo la izquierda -estimulada por los éxitos en la modernización de la Unión Soviética durante sus primeros ańos- preservará sus expectativas en la modernización técnica como camino indispensable hacia la humanización de la vida, sin embargo, en una técnica emancipada del capitalismo y bajo el dominio del proletariado y del partido comunista.
} 
político de Marx, la revolución. Si -como lo he propuesto- dejamos dialogar la antropofagia oswaldiana con pensamientos tan contrarios como los de Heidegger y Marx, descubrimos en qué medida la propuesta de Oswald de Andrade implica la refundación de lo cultural, lo político y lo religioso bajo las condiciones de la colonialidad y de la perspectiva de su superación. Pero en este diálogo tenemos que constatar también una diferencia fundamental y significativa con las teorías culturales occidentales -de Marx, Freud o Heidegger-: la cultura, la política y la religión dominantes a las cuales se refiere Oswald de Andrade no tienen su origen en Brasil y no son producidas en su propio campo cultural, político o religioso. Ellas han sido impuestas desde fuera, son resultados de la colonialidad. Si -como hemos argumentado con referencia a Marx, Freud y Heidegger- en el contexto ideológico occidental las condiciones de la dominación se ocultaron perfectamente, ello no vale en las condiciones de la colonialidad. En consecuencia, esta condición exige también otra estrategia de liberación y de emancipación. Es decir:

1. Lo que Heidegger diagnostica como "verstellt" (desplazado, bloqueado, disfrazado, disimulado, fingido), en las condiciones de la colonidad no corresponde sino a lo evidente y accesible a la experiencia.

2. No se necesita de un acto 'mesiánico' para revelar el potencial liberador de la tecnología, sino que persisten tradiciones culturales con la potencialidad de resignificar el impacto técnico.

En este sentido la antropofagia sería una práctica que no ha caído en la trampa del logocentrismo occidental que considera la propia naturaleza un objeto de explotación, y que -en su fase más avanzada- se apoya sobre un régimen estricto de trabajo (y una ética del trabajo) y sobre un uso de la tecnología que afirma su carácter de disimulación (verstellt). El movimiento antropófago insiste en el optimismo histórico -lo que explica su discurso tan jubilatorio- de que en las condiciones brasileńas las prácticas sociales disponen de la potencialidad de humanizar la técnica. Estas no necesitan de una argumentación ontológica a la manera de Heidegger o de un acto revolucionario, como lo estipula la teoría de Marx, para liberar estas potencialidades. En la 'antropofagia' y para el "hombre natural tecnizado" el uso de la técnica no se plantea con el propósito de aumentar la productividad y la explotación de la naturaleza, sino que estaría destinado a aumentar el ocio. El fin de la aplicación de los medios técnicos no es la superación de la escasez, sino servir como medio para disfrutar de la abundancia.

En correspondencia con la convicción de que en la antropofagia (a diferencia del canibalismo) no se come al otro por necesidad, sino por un motivo ritual, la antropofagia cultural transformará el propio carácter de la tecnología, que perderá su dependencia de la necesidad y entrará en contacto con el placer. 
Así, en el contexto latinoamericano no se tratará solamente de una tecnología que sirve como medio de emancipación de la colonialidad (lo que correspondería a la simple negación de su función anterior), sino de una tecnología que se integrará a una relación humanidad -naturaleza que no está determinada por la necesidad y por la explotación. Al postular que el matriarcado es el fundamento de la sociedad americana Oswald de Andrade puede imaginar una ciencia y una técnica, que "buscan producir en la tierra el cielo desde mucho tiempo y desesperadamente prometido por el Mesianismo"32.

De este modo la hipótesis del matriarcado permite a Oswald -frente a la catástrofe europea- refundar un optimismo y una dimensión liberadora y humanizadora de la ciencia y de la técnica, y denominará como "constante lúdica" al fundamento antropológico que permite pensar esta dimensión, un "sentimiento que acompaña al hombre en todas sus edades"33. "El hombre es un animal que vive entre dos grandes juguetes - el amor, donde gana (vence), y la muerte, donde pierde. Por ello inventó las artes plásticas, la poesía, el baile, la música, el teatro, el circo, y finalmente, el cine" 34 . Con su teoría de la "constante lúdica” en el ser humano, como fundamento de la cultura, Oswald de Andrade formulará una tesis que pocos años más tarde se convertirá en el argumento central de un libro que influenció profundamente el actuar cultural y político -que, aunque sin admitirlo, estaba implícitamente determinado por una teología política-, de mayo del '68 y del último movimiento revolucionario con un horizonte utópico, ("La Fantasía al poder”): me refiero al libro de Herbert Marcuse: Eros y Civilización ${ }^{35}$.

En su argumentación Marcuse se apoya en Las cartas sobre la Educación Estética de Friedrich Schiller. El escritor, historiador y poeta alemán postula en estas cartas, escritas bajo el impacto del terror de la Revolución francesa, una pulsión lúdica en el hombre, a través de la cual este se convierte en un verdadero ser humano. Probablemente para Marcuse hubiese sido más consecuente referirse a las vanguardias americanas en lugar del idealismo alemán, situando así su pensamiento en el contexto concreto de la historia de las ideas, dando razón a Oswald de Andrade

\footnotetext{
32 Op. cit. Andrade, "A crisis...", p. 133. Traducción nuestra. "A ciência e a técnica procuram produzir na terra o céu longa e desanimadoramente prometido pelo Messianismo".

33 "Ainda uma vez hoje se procura justificar politicamente as artes, dirigi-las, oprimi-las, fazê-las servirem uma causa ou uma razão de Estado. É inútil. A arte livre, brinco e problema emotivo, ressurgirá sempre porque sua última motivação resido nos arcanos da alma lúdica”. Op. cit. Andrade, "A Crisis...", p. 145.

${ }^{34}$ Ibid, p. 144.

${ }^{35}$ En el prefacio de la versión alemana, Triebstruktur und Gesellschaft (primera edición en 1957), Marcuse indica que el libro (primera edición en Boston, USA, en 1955) fue preparado en conferencias en las Washington School of Psychiatry entre 1950 y 1951, es decir, después de la "Tesis" de Oswald de Andrade.
} 
y su argumentación de que las grandes utopías europeas desde inicios del siglo XVII, como las de Moro y Campanella, habían sido profundamente influenciadas por el contacto con América.

Sí, probablemente hubiera sido más consecuente referirse a Oswald de Andrade, pero el problema es -y continúa siendo- que, con certeza, Marcuse no había leído los textos de la antropofagia cultural brasileña. Tal vez, en este sentido, puede ser considerada una justicia tardía que su propuesta de pensar la cultura, la política y la religión bajo las condiciones de la colonidad y en un mundo tecnizado ha encontrado, por lo menos en los últimos años, una recepción adecuada.

En resumen, la insistencia, como estrategia argumentativa, en lo antropofágico de la cultura brasileña y en su fundamento matriarcal, permitió a estos vanguardistas sostener una postura optimista con respecto al uso liberador de los medios técnicos modernos - contra el pesimismo que se había producido en Europa en el contexto de la Primera Guerra Mundial (un pesimismo que ya había encontrado su primera confirmación con el naufragio del Titanic en 1912). Este optimismo encontró su legitimación en supuestas constantes culturales en la historia brasileńa con la capacidad de transformar lo ajeno 'antropofágicamente'. En consecuencia, el pesimismo cultural de los pensadores y teóricos del norte y su diagnóstico pesimista no tendría validez para el Brasil. El pensamiento antropofágico le permitió a Oswald de Andrade afirmar no solamente que la apropiación de las tecnologías más avanzadas no iban a poner en cuestión la identidad brasileña, sino también que las consecuencias fatales que esta había tenido en el mundo industrializado y nórdico no iban a repetirse bajo las condiciones particulares de este país. Esta convicción alimentó la esperanza utópica de que en América Latina, precisamente en el Brasil, se preparaba la conciliación entre tecnología y humanidad y con ello una solución para una problemática frente a la cual el mundo nórdico fracasó trágicamente.

\section{REFERENCIAS}

Andrade, Oswald. "A Crise da Filosofia Messiânica". En: Andrade, Oswald: $A$ utopia antropofágica. Sáo Paulo: Editora Globo, 1990, pp. 101-147.

Andrade, Oswald. "A marcha das utopias". En: Andrade, Oswald: A utopia antropofágica. Sáo Paulo: Editora Globo, (1990): 161-209.

Andrade, Oswald. "Manifesto Antropófago". En Andrade, Oswald: A utopia antropofágica. Sáo Paulo: Editora Globo, (1990): 47-52. 
Fonseca, Maria Augusta: Oswald de Andrade. Biografia. São Paulo: Editora Globo, 2007.

Freud, Sigmund. Totem und Tabu. En: Freud, Sigmund. Gesammelte Werk, tomo IX. Frankfurt am Main: Fischer, 1999. (1 a edición 1913).

Freud, Sigmund: “Das Unbehagen in der Kultur”. En: Freud, Sigmund. Gesammelte Werke, tomo XIV. Frankfurt am Main: Fischer. 1999 (1ª edición 1930): 419-506.

Giucci, Guillermo. La vida cultural del automóvil. Buenos Aires: Prometeo Libros, 2007.

Heidegger, Martin. Die Technik und die Kehre. Pfullingen: Neske, 1962.

Heidegger, Martin: "Der Ursprung des Kunstwerkes". In Heidegger, Martin: Holzwege. Frankfurt am Main: Vittorio Klostermann, (1980): 1-72.

Heidegger, Martin. "La pregunta por la técnica". Disponible en: http://www. heideggeriana.com.ar/textos/tecnica.html. [Consultado el 15 de noviembre de 2015].

Heidegger, Martin. "La vuelta". Disponible en: http://www.heideggeriana.com.ar/ textos/la_vuelta.html. [Consultado el 15 de noviembre de 2015].

Horkheimer, Max y Adorno, Theodor. Dialektik der Aufklärung. Frankfurt: Fischer, 2000 (1ª edición 1947).

Jauregui, Carlos A. Canibalia. Canibalismo, calibanismo, antropofagia cultural y consumo en América Latina. Madrid: Vervuert, 2008.

Keck, Anette, Inka, Kording \& Anja, Prochaska (eds.). Verschlungene Grenzen Antropophagie in Literatur und Kulturwissenschaften. Literatur und Anthropologie. Tomo 2, Tübingen: Narr, 1999.

Kittler, Friedrich. Grammophon Film Typewriter. Berlin: Brinkmann \& Bose, 1986.

Marcuse, Herbert. Triebstruktur und Gesellschaft. Frankfurt am Main: Suhrkamp, 1968. 
Marx, Karl. Das Kapital. Berlin: Dietz Verlag, 1970.

Nitschack, Horst. "O mito do índio no modernismo brasileiro e nas vanguardas hispanoamericanas.” En: Berg, Walter Bruno. As Américas do Sul: O Brasil no Contexto Latino-Americano. Beihefte zur Iberoromania Bd. 17. Tübingen: Max Niemeyer, (2001): 108-118.

Nunes, Benedito: "Antropofagia ao Alcance de todos". En: Andrade, Oswald. $A$ utopia antropofágica. São Paulo: Editora Globo, (1990): 5 - 39.

Rocha, João Cezar de Castro y Ruffinelli, Jorge (Eds.). Anthropophagy Today? Nuevo Texto crítico. Año XII, (1999), No. 23/24.

Santiago, Silviano. "O Entre-lugar do Discurso Latino-americano". En: Santiago, Silviano. Uma literatura nos trópicos. São Paulo: Editora Perspectiva, (1978): 11-28.

Schwartz, Jorge. Vanguardas latino-americanas; polémicas, manifestos e textos criticos. São Paulo: Edusp; Iluminuras; Fapesp, 1995.

Schwarz, Roberto. "Idéias fora do lugar". En: Schwarz, Roberto. Ao vencedor as batatas. São Paulo: Livraria Duas Cidades, 1992 (1ª edición 1977): 13-28.

Sevcenko, Nicolau. Orfeu extático na Metrópole. São Paulo, sociedade e cultura nos frementes anos 20. Sáo Paulo: Compahia das Letras, 1992. 